\title{
Erratum to: Improving Access and Quality of Public Services in Latin America
}

\author{
Guillermo Perry and Ramona Angelescu Naqvi
}

(C) The Author(s) 2017

G. Perry, R. Angelescu Naqvi, Improving Access and Quality of

Public Services in Latin America, Latin American Political Economy, DOI 10.1057/978-1-137-59344-3

DOI 10.1057/978-1-137-59344-3_6

The original version of the book contained an error which has been corrected. The correction is given below:

The Foreword was not included in the original version of the book.

The updated original online version for this book can be found at DOI http://dx.doi.org/10.1057/978-1-137-59344-3 